\title{
A invenção de um país de empreendedores sociais: "Imagina na Copa" e seu projeto de Brasil ${ }^{1}$
}

\author{
Vander Casaqui
}

\section{Resumo}

Este estudo trata do tema do empreendedorismo social, a partir de sua dimensão discursiva, através da análise do projeto "Imagina na Copa", uma plataforma digital que dá visibilidade a iniciativas de empreendedores sociais brasileiros. 0 "projeto de comunidade" permite compreender a articulação do papel social (DAHRENDORF) do empreendedor social no país imaginado, no qual os jovens brasileiros são protagonistas e agentes da "transformação" - articulada entre a atitude positiva individual e o trabalho cooperativo. 0 quadro teórico trata dos significados do empreendedorismo social, de sua relação com o espírito do capitalismo, de seu caráter de discurso social (ANGENOT); as análises do corpus são realizadas a partir da proposta teórico-metodológica da análise do discurso.

\section{Palavras-Chave}

Empreendedorismo social. Comunicação e discurso. Sociabilidade. Consumo. Comunidade.

Vander Casaqui | vcasaqui@yahoo.com.br Doutor em Ciências da Comunicação pela Universidade de São Paulo USP, com Pós-doutoramento pela Universidade Nova de Lisboa. Professor do Programa de Pós-graduação em Comunicação e Práticas de Consumo da Escola Superior de Propaganda e Marketing - ESPM.

\section{Introdução}

"IMAGINE CONSTRUIR 0 PAÍS QUE QUEREMOS VER PARA A COPA DO MUNDO E PARA DEPOIS DELA. É isso que queremos fazer." É dessa forma, em letras garrafais e tom grandiloquente, que a convocação para a imaginação de um outro país é feita pelo projeto Imagina na Copa, objeto deste estudo. 0 "projeto de mobilização", como se autodefine a iniciativa, apresenta-se como totalidade que organiza o olhar para certo Brasil, pela ótica de uma cena que vem ganhando espaço em nossa sociedade e em outras partes do mundo, a cena do empreendedorismo social. Aproximamonos das relações entre comunicação e sociabilidade na perspectiva de "investigar como modalidades de comunicação produzem ou se agenciam com processos de sociabilidade", com o objetivo de "apreender 0 fato comunicacional em sua complexidade e em conexão com outros fenômenos de ordens diversas" (CAIAFA; ELHAJJI, 2007, p. 7). Nesse sentido, o empreendedorismo social tem seu interesse como fenômeno essencialmente comunicacional, por meio dos discursos que alimentam a significação de seu papel social 
(DAHRENDORF, 2012). 0 projeto Imagina na Copa é um exemplo recente e relevante na cena brasileira, como plataforma de divulgação, que constitui um regime de visibilidade para iniciativas de brasileiros identificadas com uma visão "positiva" e "transformadora" do país. Essencialmente, trata-se de um empreendimento pautado pela comunicação como elemento fundante de sua esfera produtiva, de seu modus operandi. A descrição do projeto por si mesmo é reveladora da proposta de país em jogo e de formas de sociabilidade calcadas no ativismo, na ação social, subvertendo a lógica da postura crítica do brasileiro em relação à organização da Copa do Mundo de 2014 no Brasil, sintetizado pela expressão "Imagina na Copa":

0 Imagina na Copa é um projeto de mobilização que busca promover uma virada para o Brasil até 2014. Como? Mostrando que pessoas como você têm, sim, o poder de construir um país meIhor, despertando cada um para seu potencial de transformação.

Nosso trabalho é divulgar iniciativas reais que ajudam a vida das pessoas e também reunir e organizar gente que está a fim de construir um país melhor. Para nós, a vitória do Brasil na Copa do Mundo é muito mais importante fora dos campos. Estamos vivendo um momento único para mudar nossa atitude e aproveitar ao máximo para botar a mão na massa. Bora? ${ }^{3}$

A "proposta de mobilização" é traduzida por um regime de convocação biopolítica (PRADO,
2013), em que a divulgação tem como propósito a constituição de um elo social que transita entre 0 sentido coletivo e o plano individual. Dessa forma, para "reunir e organizar" com vistas a "construir um país melhor", é preciso "despertar o potencial" de cada um. Esse processo seria essencialmente pautado pelo consumo midiático (SILVERSTONE, 2002, p. 150) das imagens de "pessoas como você" transpostas para a linguagem audiovisual, os vídeos que materializam esse mapeamento do Brasil imaginado pelo Imagina na Copa.

\section{Empreendedorismo social, (in)definições conceituais e perspectiva histórica}

No caso específico do Brasil, um impulso decisivo para a difusão das iniciativas e dos empreendedores sociais foi o documentário Quem se importa?, dirigido por Mara Mourão e lançado em 2011, no qual os protagonistas são sujeitos identificados por essa denominação e seus depoimentos. Assim, são apresentados seus projetos, suas histórias pessoais, seus ideais, suas leituras do papel que ocupam, ou que esperam ocupar na sociedade.

0 filme se tornou porta-voz e divulgador da cena empreendedora social, não somente brasileira, mas também de outros países, como Portugal, onde tem sido apresentado em universidades e em eventos voltados a incentivar as iniciativas do

Trabalho apresentado ao Grupo de Trabalho Comunicação e Sociabilidade do XXIII Encontro Anual da Compós, na Universidade Federal do Pará, Belém, de 27 a 30 de maio de 2014.

Disponível em: <http://imaginanacopa.com.br/sobre/>. Acesso em: 9 fev. 2014.

Disponível em: <http://imaginanacopa.com.br/sobre/>. Acesso em: 9 fev. 2014. 
gênero. 0 grande paradigma do empreendedor social no mundo, presente no filme com destaque, é 0 economista bengalês Muhammad Yunus, fundador do Grameen Bank (Banco da Aldeia), um dos pioneiros na área de microcrédito voltado aos "pobres", em 1983; por sua atuação através dessa iniciativa, foi o vencedor do Prêmio Nobel da Paz em 2006. Em seu discurso, defende o conceito de economia social, como reproduzimos a seguir:

0 negócio social é um negócio orientado a uma causa. Em uma empresa social, os investidores/ proprietários podem gradualmente recuperar 0 dinheiro investido, mas não podem tomar qualquer dividendo para além desse ponto. 0 objetivo do investimento é puramente atingir um ou mais objetivos sociais através da operação da empresa, nenhum ganho pessoal é desejado pelos investidores. A empresa deve cobrir todos os custos e fazer lucro, ao mesmo tempo alcançar o objetivo social, (...) de uma forma empresarial (tradução nossa). ${ }^{4}$

Nesse ponto, começam os paradoxos e as (in) definições em torno da noção genérica de "setor cidadão", como deixa transparecer o manual didático do filme Quem se Importa?5, 0 qual se autodefine como "um movimento":

0 chamado "setor cidadão" é jovem e os conceitos mudam rapidamente. Ativistas, transformadores, agentes de mudança, líderes sociais, são alguns dos nomes utilizados para definir as pessoas que souberam entender as necessidades da sociedade saindo da apatia e do imobilismo para agir concretamente em busca de soluções para as grandes questões da humanidade (p. 10).
Os esforços para a definição do conceito de empreendedorismo social, derivados dos estudos que enfatizam ora as características do empreendedor social, ora os processos do empreendedorismo social, ora os resultados gerados por essa atividade (do "puramente" social ao socioeconômico), têm se desdobrado em quatro temas comuns, segundo Trivedi e Stokols (2011, p. 7, tradução nossa):

(i) ênfase em "objetivos sociais", em oposição aos ganhos econômicos, (ii) o papel ativista social desempenhado pelo empreendedor social, (iii) elementos de empreendedorismo e inovação (pelo menos na maioria dos exemplos) e (iv) a criação e utilização do lucro econômico como um meio para resolver um problema social e não como um fim em si mesmo.

Em todas as abordagens, um ponto essencial: o empreendedorismo social se apoia na aura do termo "social", que significa um agente e seu campo de atividade. Para Martin e 0sberg (2007), a imprecisão se multiplica quando se dá a junção dos termos "empreendedor" e "social”; se há dificuldade em se definir o que é 0 empreendedorismo, o termo "social" pressupõe a mudança de algo difícil de apreender, de delimitar de forma clara. Diante dessa situação, em relação a este estudo, localizamos a cena do empreendedorismo social por meio da dinâmica dos discursos articulados em relação dialógica com sua denominação. 
Apesar de ser tratado como um fenômeno

relativamente novo, as raízes históricas dos

princípios e valores comumente associados ao empreendedorismo social, e, de modo abrangente, aos movimentos da economia social, remontam à Antiguidade Clássica ou Oriental, e a formas de organização coletiva em operação na Europa da era medieval. Suas origens contemporâneas são localizadas no século XIX, em uma combinação de elementos advindos de vertentes distintas, muitas vezes contraditórias, que irão constituir o chamado terceiro setor, como o socialismo utópico, 0 liberalismo e o social-cristianismo (QUINTÃo, 2012, p. 128-130). Essa origem mais recente se dá pela emergência da "questão social", ou seja, "a tomada de consciência da fratura social que bipolarizou a sociedade do século XIX, colocando de um lado o proletariado, obrigado a vender a sua força de trabalho, e do outro os detentores do capital" (idem, p. 130). A filantropia, as fundações, as caridades, as misericórdias, as cooperativas, o voluntariado estão entre as iniciativas de reação às fraturas sociais decorrentes do avanço da Revolução Industrial e de suas consequências para a vida dos trabalhadores.

Se, de acordo com Quintão, temos na origem a desigualdade pautada pelas relações de exploração do trabalho, que foi o foco das análises e diagnósticos sobre a economia e a sociedade capitalista por autores como Karl Marx, em nossos dias as desigualdades sociais se multiplicam. Simultaneamente, expande-se a relação com a ideia de fratura social resultante das falhas do sistema capitalista e suas consequências, por exemplo, no tocante à crise do Estado do Bem-

Estar Social, ou Estado Providência.

Identificamos um amplo espectro de nomeações, definições, formas de atuação, comumente associadas ao chamado Terceiro Setor, mas não restritas a ele, as quais transitam no campo semântico do termo "empreendedor social", dada a sua visibilidade no momento atual. Economia social, negócio social, intraempreendedorismo social, inovação social, mercado social, negócios de impacto social, valor social, objetivos sociais... Enfim, termos que compõem a esfera mercadológica, associados ao termo "social", que serve à lógica de deslocamento semântico. 0 mercado, regido pela competitividade, pelo lucro, pelo compromisso com o sistema capitalista que lhe dá sustentação e sentido, ganha uma aura na combinação dos termos, evidenciando a mutação retórica do capitalismo contemporâneo. 0 recente empreendedorismo social, conceito difundido e institucionalizado especialmente a partir da década de 1990 (DEFOURNY, 2009), ressignifica muitas das iniciativas já existentes, lançando-as sobre outro enfoque, 0 da competitividade e do diálogo aberto com as questões colocadas pelo próprio mercado, sintetizadas pelo termo mutante "sustentabilidade". Essa denominação desencadeia também projetos e ações de sujeitos ajustados ao novo modelo, que imaginam sua atuação a partir desses pressupostos. A combinatória entre 0 espírito do tempo, os meios técnicos disponíveis, as denominações em evidência, molda a proposta do Imagina na Copa, o projeto analisado neste trabalho. 


\section{Cultura e empreendedorismo social}

Peter Drucker (2011, p. 349), uma das principais referências sobre empreendedorismo, considera, ainda nos anos 1980, que "precisamos é de uma sociedade empreendedora, na qual a inovação e 0 empreendimento sejam normais, estáveis e contínuos". 0 autor pensa 0 futuro ideal sob a ótica da economia capitalista, em que a inovação e 0 empreendimento tornam-se uma "atividade vital, permanente e integral em nossas organizações, nossa economia, nossa sociedade" (idem). Essa perspectiva ampla de sociedade projetada por Drucker se ajusta tanto à noção de empreendedorismo social, quanto, implicitamente, compreende a disseminação do espírito

empreendedor pelas mais diversas esferas da vida, para além do mundo do trabalho e dos negócios.

Sua concepção de sociedade empreendedora passa por uma rejeição à ideia de "revolução":

"sabemos agora que 'revolução' não é realização e o novo amanhecer. Ela resulta de decadência senil da falência de ideias e instituições, do fracasso da auto-renovação" (ibidem, p. 348).

\section{A rejeição à compatibilidade entre sociedade} empreendedora e revolução entra em choque com os discursos que vinculam o espírito revolucionário ao papel social (DAHRENDORF, 2012) do empreendedor e, especialmente, do empreendedor social em nosso tempo. Na contemporaneidade, o sentido de "revolução", esvaziado de seu caráter de ruptura radical da ordem vigente, de mudanças estruturais, é marcado como um atributo indissociável da atuação tanto de empreendedores quanto de empreendedores sociais. Se a geração de maio de 1968 queria mudar o mundo, hoje o sujeito que assumiria essa missão transformadora parece ser o empreendedor social - a Ashoka, uma das principais organizações no mundo que incentivam 0 empreendedorismo social, nomeia seus agentes como changemakers.

Nesse sentido, a análise de Drucker tem involuntário alinhamento com a tese do novo espírito do capitalismo (BOLTANSKI; CHIAPELLO, 2009), desenvolvida na década de 1990. Naquele momento histórico, a lógica empreendedora era percebida pelos autores como manifestação do espírito do tempo, a transbordar do mundo do trabalho para fomentar o imaginário cotidiano, tensionar os sujeitos em suas práticas diárias, alimentar uma cadeia de produção, circulação e consumo de discursos materializados em bens culturais, como livros, filmes, cursos, etc. 0 empreendedorismo agregou os sentidos da motivação para que 0 capitalismo renovasse sua retórica e se tornasse atraente para as novas gerações. 0 processo de atração de novos quadros é tido pelos autores como fundamental para a força do capitalismo, que teria superado outros sistemas econômicos por sua capacidade de assimilar os discursos de seus críticos, para se reconstituir a partir dessa assimilação. Esse motor retórico, ciclicamente retroalimentado, reveste o capitalismo com 0 apelo de novos estímulos ao engajamento no próprio sistema, para continuar 
a ser "inspirador" aos quadros de trabalhadores, empreendedores, agentes das gerações seguintes. Podemos perceber, por exemplo, como grandes corporações se alimentam desse discurso na contemporaneidade, quando tratam agentes de seus quadros como "intrapreendedores" ("intrapreneurs"), algo verificável no texto The art of intrapreneurship (2013), elaborado por Guy Kawasaki, Advisor da Motorola Mobility. ${ }^{6}$

Esse espírito do capitalismo persiste e parece ganhar força na contemporaneidade; porém, há algo de novo na forma como o empreendedor social passa a agregar os valores e significados do engajamento de novos quadros no sistema capitalista. Se há 0 "intrapreendedor", hoje há também 0 "intrapreendedor social" ("social intrapreneur"), ou seja, o empreendedor social, agora de maneira explícita, é incorporado ao sistema capitalista para renovar a cultura organizacional e projetá-la para um futuro imaginado pelo próprio sistema. Nesse sentido, o capitalismo assume um discurso utópico, ao planejar um "outro lugar", ou um "não lugar" (significados originários das utopias), que, na verdade, é 0 "mesmo lugar", 0 mesmo sistema repaginado para se manter como hegemônico.

A significação do papel do empreendedor social lhe caracteriza, em certa medida, como um "herói de todos os dias" (BUONANNO, 2011, p. 70). Segundo a autora, os heróis reconhecidos hoje em dia são aqueles confundidos com as pessoas normais, pois representam a inspiração próxima, o "espelho" para uma sociedade pautada pelo pragmatismo, pelo exemplo prático, por aqueles que "fazem acontecer". Esse processo se estabelece como paradoxal, uma vez que "tal reconhecimento das virtudes heroicas seja tão amplamente conferido que acaba diminuindo-as - como praticamente todos são heróis, mesmo que heróis de todos os dias, obviamente ninguém é um herói” (idem).

\section{$4 \mathrm{~A}$ abordagem discursiva do empreendedorismo social}

A visibilidade da cena empreendedora social tem vinculação direta com os meios técnicos e com a cultura digital contemporânea. 0s modos de presença no ambiente midiático são a tradução de ideias e projetos em andamento para a forma mercadoria, para produtos culturais relacionados de maneira intrínseca com a lógica publicitária, e, em última instância, com a estética da comunicação mercadológica:

As instituições do Estado, as organizações intergovernamentais, as coletividades locais e territoriais, até associações humanitárias tão diferentes como Médicos sem Fronteiras, Greenpeace ou Anistia Internacional não hesitam mais a fazer apelo ao savoir-faire da comunicação publicitária em matéria de construção de uma imagem e de uma identidade (MATTELART, 2002, p. 395).

A forma mercadoria é parte fundamental da construção dos projetos de empreendedorismo 
social, uma vez lançados à lógica neoliberal da concorrência, no que tange a concursos, prêmios do campo, e, principalmente, à busca por investimentos capazes de proporcionar a viabilidade e a sustentabilidade das iniciativas. Ideias para solucionar problemas sociais, diagnósticos sobre a situação do país, justificativas sobre a relevância de uma causa, argumentos sobre sua eficácia, seus impactos e sua performance mercadológica - a esses elementos semânticos correspondem sínteses imagéticas, recursos estéticos, representações icônicas desse micromundo construído como projeto. Dessa maneira, os projetos se lançam a um mercado dos discursos, como defende Angenot (2010, p. 79); uma economia das ideias, dos temas, em que os "objetos ideológicos encontram nichos de difusão e se esforçam por captar públicos fiéis, cujas necessidades modelam de acordo com a natureza da oferta" (idem). Nesse mercado se estabelece um compromisso clássico para qualquer mercado de consumo moderno: "a novidade previsível, ou a arte de fazer algo novo com o velho" (ibidem). Esse processo de mercantilização de ideias e sua tradução para a lógica publicitária permite compreender como a emergência da denominação "empreendedor social" ganha o valor simbólico da inovação, da novidade, transferindo-0 para aqueles que assumem esse discurso e redefinem sua atuação.

Angenot compreende a trama discursiva da sociedade a partir do paradigma do dialogismo bakhtiniano, ou seja, dos embates ideológicos, das disputas entre os discursos pelo significado. Nesse ambiente social de interação generalizada, os enunciados, vinculados a cadeias ideológicas, "são reflexos uns dos outros, estão 'plenos de ecos e de recordações', atravessados por 'visões de mundo, tendências, teorias' de uma época" (ANGENOT, 2010, p. 25). 0s discursos sobre o empreendedorismo social e os discursos dos projetos se constituem na interação, na interdependência, no diálogo com enunciados anteriores, contemporâneos e na antecipação de cenários futuros. Em relação a esse último aspecto, observamos os projetos de empreendimentos sociais, estejam em implantação ou não, como concepções de mundos possiveis (LAZZARATO, 2006). Nesse sentido, as organizações produzem cenários por meio de processos comunicacionais, através dos quais trabalhadores e consumidores são alinhados em sintonia com missões, valores, objetivos corporativos. Independentemente do caráter do negócio, seja social ou não, a noção de mundos possíveis a partir de doutrinas corporativas, conforme discute Mattelart (2002) a respeito das utopias planetárias contemporâneas, coloca a questão dos conflitos e sobreposições entre espaço público e privado, bem comum e interesses particulares.

Dey e Steyaert (2010, p. 88), em abordagem narrativa do empreendedorismo social e seus efeitos políticos, tratam esse tema como "uma grande narrativa, que compreende, entre outras coisas, um alto grau de univocidade, ausência de ambiguidade, unilateralidade, bem como uma 
reforma quase religiosa" (tradução nossa) ${ }^{7}$.

Como produção simbólica, o empreendedorismo

social é apontado como algo que não é novo, todavia, é baseado em um "amálgama de ideias" que encontrou um novo território para sua aplicação (p. 96), enfim, um território simbólico.

Essa noção será explorada nas análises dos discursos do projeto Imagina na Copa.

\section{Análise discursiva do projeto Imagina na Copa}

0 Imagina na Copa foi lançado em 2012, inicialmente como projeto em busca de captação de recursos, através da plataforma Catarse (http://catarse.me/ pt/imaginanacopa), tendo arrecadado $\mathrm{R} \$ 25.560,00$ oferecidos pelo total de 294 apoiadores, superando, com isso, a meta de $\mathrm{R} \$ 20.000,00$ para sua realização.

0 financiamento via crowdfunding, que consiste na divisão do projeto em cotas, pagas pelos apoiadores somente quando atingida a meta estipulada, é um modelo adotado na cena do empreendedorismo social paulistano, tendo a plataforma Catarse como um de seus atores mais recorrentes. A equipe do Imagina na Copa, composta por quatro jovens, estabeleceu como objetivo a produção de 75 vídeos semanais, com a finalidade de "mudar a atitude" dos jovens brasileiros:
Desde junho deste ano, os jovens foram para as ruas pedir um país melhor. Segundo estudo realizado pela Box1824, $79 \%$ dos jovens querem utilizar parte do seu tempo para ajudar a sociedade. Esta é nossa oportunidade de abandonar uma visão pessimista e conquistar a confiança de que podemos, sim, transformar as coisas para melhor. ${ }^{8}$

Tendo como materialidade a produção audiovisual, esse "projeto de comunidade", como se autointitula na apresentação da plataforma Catarse, estabelece-se como uma proposta de totalidade. Um território simbólico cuja proposta é oferecer exemplos para a inspiração de jovens, os agentes eleitos para a mudança social almejada. Dessa forma, 0 Imagina na Copa se coloca como mediação entre um país a ser transformado e um país onde essa transformação está em curso; seu regime de visibilidade é, simultaneamente, um regime de convocação para a mudança. 0 ponto de partida do projeto são os resultados de uma pesquisa realizada pela Box $1824^{9}$ (agência que realiza 0 levantamento de tendências e comportamentos, com especial foco nos jovens), a qual aponta o interesse dos jovens em se dedicar a "ajudar a sociedade". Na trajetória de sua execução, 0 Imagina na Copa significa os acontecimentos de junho de 2013, as manifestações que

No original: "The grand narrative of social entrepreneurship comprises, among other things, a high level of univocity, unambiguousness, one-sidedness as well as a quasi-religious makeover".

Disponível em: <http://imaginanacopa.com.br/sobre/>. Acesso em: 16 fev. 2014.

Pesquisa "Sonho brasileiro", realizada com jovens entre 18 e 24 anos, que se apresenta como "um estudo aberto, sem viés de consumo, sem fins lucrativos, que visa ouvir a primeira geração global de brasileiros para entender seus valores, a forma como enxerga o país, os papéis que se propõe a desempenhar nele e os cenários futuros em que se vê atuando" (PROJETO SONHO BRASILEIRO, 2011). 
tomaram as ruas do país, para traduzi-las como "oportunidade" de mobilização e de adoção de uma "atitude positiva". Como observam Berger e Luckmann (1996, p. 92), "o edifício das legitimações é construído sobre a linguagem e usa-a como seu principal instrumento".

A proximidade com o cenário construído pela pesquisa da Box1824 é ainda maior quando se considera a relação entre a noção de "jovemponte", apresentada como tendência de um Brasil em transformação, e a lógica operacional do Imagina na Copa, discutida a seguir. Em ambos os casos, o jovem é projetado por meio de um perfil que guarda nítida semelhança com a noção do homem conexionista, identificado com o novo espírito do capitalismo. Na definição do jovem-ponte, temos a função primordial baseada em "redistribuir estes pensamentos e ideias [recolhidos em seu trânsito por diferentes grupos], conectando redes e pessoas que nunca se falariam" (PROJETO SONHO BRASILEIRO, 2011). Por sua vez, o homem conexionista, definido por Boltanski e Chiapello (2009, p. 466), tem como característica "a adaptabilidade, ou seja, a capacidade de tratar sua própria pessoa como um texto que poderia ser traduzido para diferentes línguas". Essa exigência para circular nas redes está ajustada à atividade de tornar produtivas as relações interpessoais, o que é lido de forma crítica pelos autores: "a utilização estratégica de relações, apresentando certos traços atribuíveis à amizade em outros contextos, tem o dom de criar perturbações quando é possível tirar vantagens financeiras das atividades de conexão" (idem, p. 460). Acrescentaríamos a esse diagnóstico a aquisição de capitais simbólicos, sociais, uma vez que a cena empreendedora social premia e dá destaque a seus personagens modelares.

Conforme Fairclough (2001, p. 92), "a prática discursiva é constitutiva tanto de maneira convencional como criativa: contribui para reproduzir a sociedade (identidades sociais, relações sociais, sistemas de conhecimento e crença) como é, mas também contribui para transformá-la". Nesse sentido, o Imagina na Copa se apoia na cultura das redes digitais, do compartilhamento de informações e da interatividade, para constituir o seu território simbólico. A base comunicacional digital, amplamente difundida nas relações sociais juvenis, serve como linguagem para mobilizar para a "mudança". Observamos sua entrada em cena na rede de relacionamentos Facebook (Fig.1), na qual são publicadas mensagens do projeto e são divulgados os vídeos de empreendimentos sociais brasileiros, também disponíveis no canal do Imagina na Copa no Youtube.

0 modus operandi do projeto parte de um processo de produção, circulação e consumo das mensagens com vistas à construção da "transformação" do país. Sua divulgação na página do Facebook (Fig.2) evidencia o contrato comunicativo (CHARAUDEAU, 2007) entre 0 Imagina na Copa e seus seguidores, implicados como consumidores dos "pacotes biopolíticos" (PRAD0, 2012, p. 172), elaborados 
Figura 1: Imagem da página do projeto Imagina na Copa na rede Facebook.

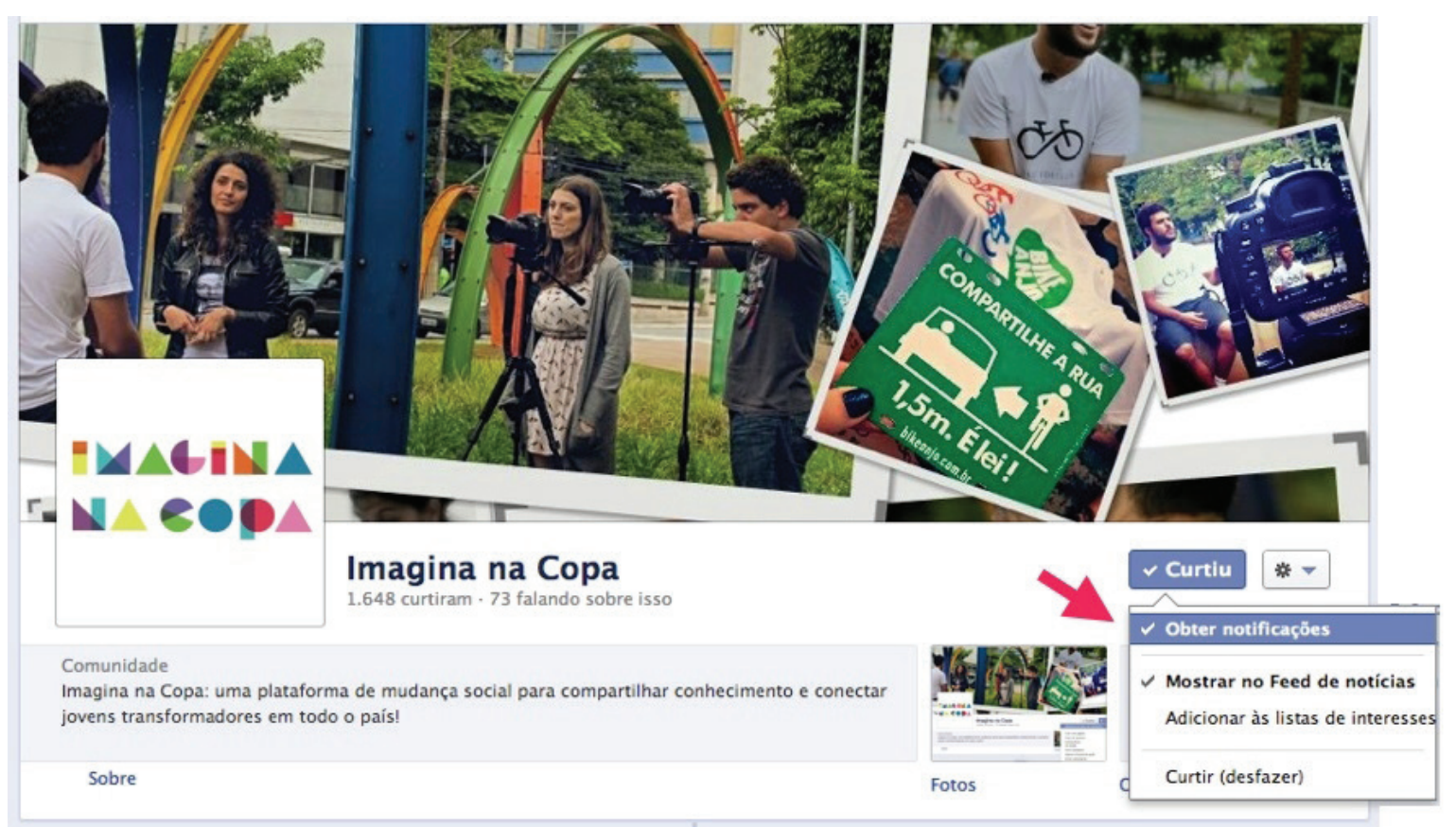

Fonte: publicação no perfil do projeto em 10 dez. 2012.

a partir de linguagem lúdica, colorida, vibrante, essencialmente juvenil.

A proposta do Imagina na Copa sintetizada no banner se baseia na representação de uma cadeia de produção, circulação e consumo. No que se refere à esfera produtiva, temos uma tradução do mundo do trabalho à lógica empreendedora do novo espírito do capitalismo (BOLTANSKI; CHIAPELLO, 2009). Sua convocação tem como meta 0 engajamento juvenil, tendo como território simbólico o Imagina na Copa e como forma de atuação um sentido de trabalho cooperativo. Essa lógica de trabalho cooperativo sob a égide do empreendedorismo social inclui tanto o projeto, como sujeito que assume o papel de mediador e de agregador de um sentido de comunidade, quanto os sujeitos que são ativados pelas histórias divulgadas.

Caracterizados como personagens de uma história imaginada, um tipo de desenho animado, os agentes representados no processo de trabalho em torno do Imagina na Copa atualizam a projeção futura sobre o mundo do trabalho feita por McLuhan, na década de 1960. A tese do pesquisador canadense é baseada na associação com a imagem do artista, transposta como paradigma de uma noção de trabalho que substitui o vínculo empregatício pela atuação em papéis e projetos, na conjunção orgânica entre atividade laboral e lazer: "[0 artista] nunca está trabalhando. Está fazendo o que gosta de fazer. Está se divertindo e desfrutando de seu lazer 0 


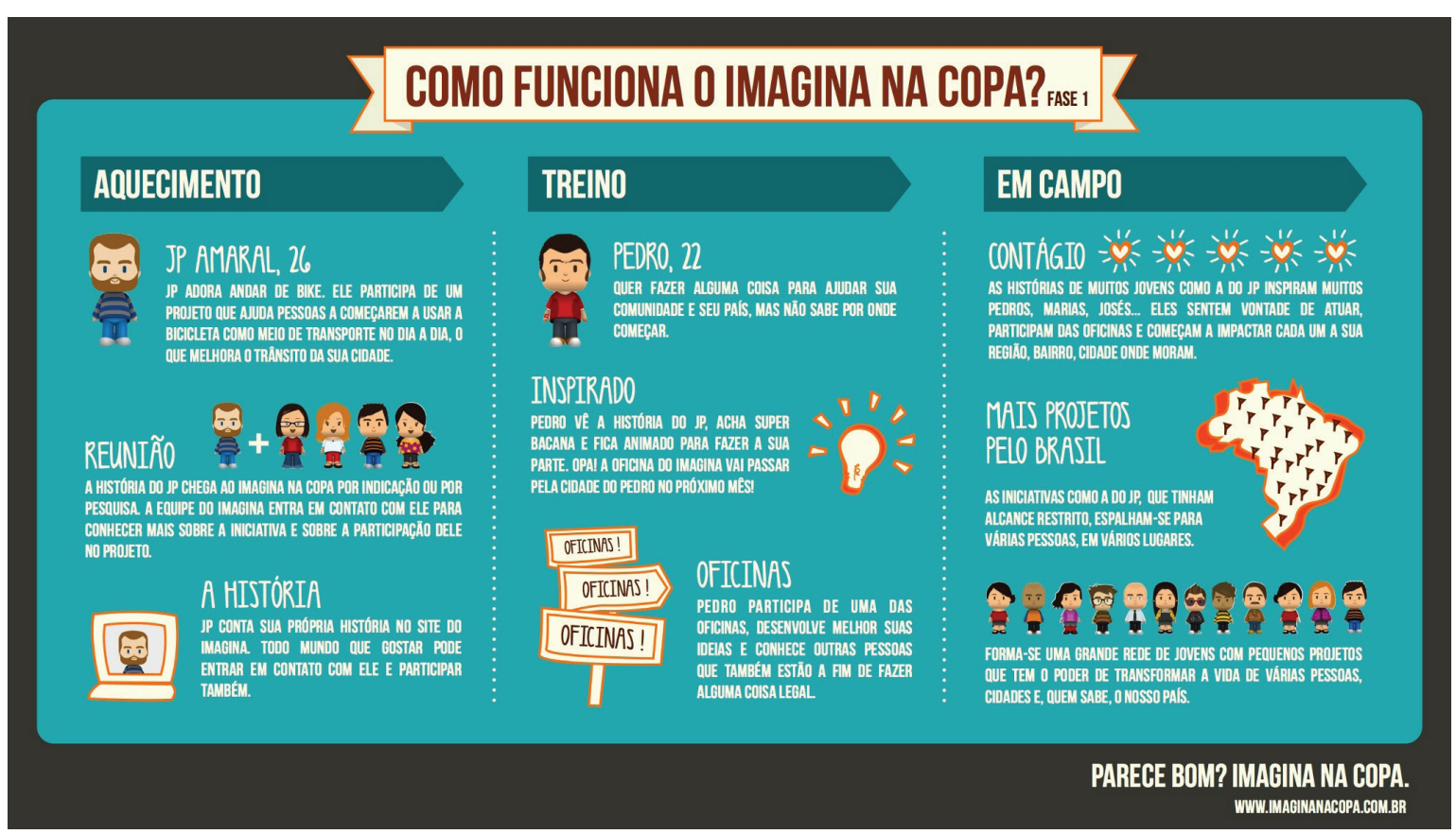

Fonte: publicação no perfil do projeto em $1^{0}$ jan. 2012.

tempo todo, especialmente quando trabalha mais intensamente" (McLUHAN, 2005, p. 183). No caso do projeto Imagina na Copa, o trabalho de engajamento é representado por sujeitos desenhados em estado de satisfação, traduzida por feições sorridentes. A lógica da atitude positiva é transposta para essa figurativização, em que também existem rastros de uma leitura da diversidade e da multiculturalidade associadas ao povo brasileiro, mais especificamente aos jovens. Os doze bonecos (presentes no canto inferior direito da imagem) caracterizam uma ideia de comunidade em torno do projeto; há a junção entre a uniformidade do padrão dos personagens e suas diferenças de cor de pele, de cabelos, bem como suas distinções baseadas em estilos de vida sugeridos pelos modos de vestir.
Os processos de consumo estão diretamente relacionados com a noção de prosumer, de um consumidor que também é produtor; no caso do objeto deste estudo, o consumo simbólico das narrativas e dos pacotes biopolíticos do projeto implica na transformação do sujeito, que, por sua vez, seria o disseminador da mudança ocorrida em si mesmo para o outro. Essa cadeia imaginada é complementada com os elementos relacionados com a circulação.

A noção de circulação pode ser percebida como 0 circuito em que as mensagens, as narrativas audiovisuais produzem o elo social no mundo possível do Imagina na Copa. 0 sujeito que se propõe a tornar pública a sua história faz parte de 
um processo de "inspiração" e "contágio". No caso do primeiro termo, claramente vemos a noção de histórias exemplares, com nuances em relação à tese de Buonanno (2011): as histórias combinam a vida com o trabalho, ou tornam indissociáveis os dois elementos, caracterizando, assim, um espírito do empreendedor social calcado na relação entre trabalho e felicidade. Uma ética própria permeia a imagem desse ator social, o sujeito potente capaz de desencadear a "transformação", derivado da combinatória entre vocação e atitude positiva. No que se refere ao "contágio", há mais uma referência ao espírito do tempo, permeado pela cultura digital; o contágio é a denominação que traduz a ideia da disseminação em rede da informação nesse ambiente.

0 exercício de imaginação do qual resulta 0 projeto de uma teia social jovem e conectada, capaz de gerar a "transformação", vê-se às voltas com a incerteza da materialização desse processo de mudança a ser desencadeado pelo Imagina na Copa, como se pode perceber no trecho: "forma-se uma grande rede de jovens com pequenos projetos que tem o poder de transformar a vida de várias pessoas, cidades e, quem sabe, o nosso país". A incerteza da expressão "quem sabe" contrasta com a visão positiva do processo de transformação social. Permite entrever o projeto de sociedade em sua dimensão do "sonho" falível, em que o individual e 0 coletivo se combinam, porém, o elo social articulado com a perspectiva de país parece carecer de um contrato social mais abrangente.
A ausência do Estado nesse projeto juvenil sugere a pertinência da tese de Dey e Steyaert (2010, p. 88), de que o empreendedorismo social se constitui como grande narrativa, em um registro quase religioso, em tom messiânico: é preciso "acreditar", ter "força interior", "atitude positiva" para que a transformação proposta aconteça, como podemos observar nos dois exemplos a seguir (Figs. 3 e 4).

A orquestração de vozes, no sentido da teoria bakhtiniana, demonstra a relação entre "mudar o mundo" e "mudar a si mesmo" como partes inerentes de um mesmo processo; 0 estado de espírito positivo, nesse caso, atribuído à voz do outro, entre eles Gandhi (e não "Ghandi”, como aparece na página seguinte), é difundido por meio de uma estratégia de legitimação da fala.

A multiplicidade de vozes de empreendedores sociais (Fig.5), apresentada por meio dos vídeos do projeto, sugere uma nação de "gente que faz". A ideia de comunidade constituída por histórias de sujeitos distintos, atuando e transformando realidades locais das mais diversas, é a perspectiva de nação baseada na junção de imagens, de narrativas, articuladas sob a liderança do Imagina na Copa. 0 esforço de tornar visíveis as narrativas inspiracionais materializa um projeto de utopia pragmática, em que 0 "outro lugar", ou o "não lugar", estaria em gestação, em germinação, precisando somente da mediação do território simbólico do Imagina na Copa para "contagiar" e "transformar" o país. 
Figuras 3 e 4: Imagens da página do projeto Imagina na Copa na rede Facebook.
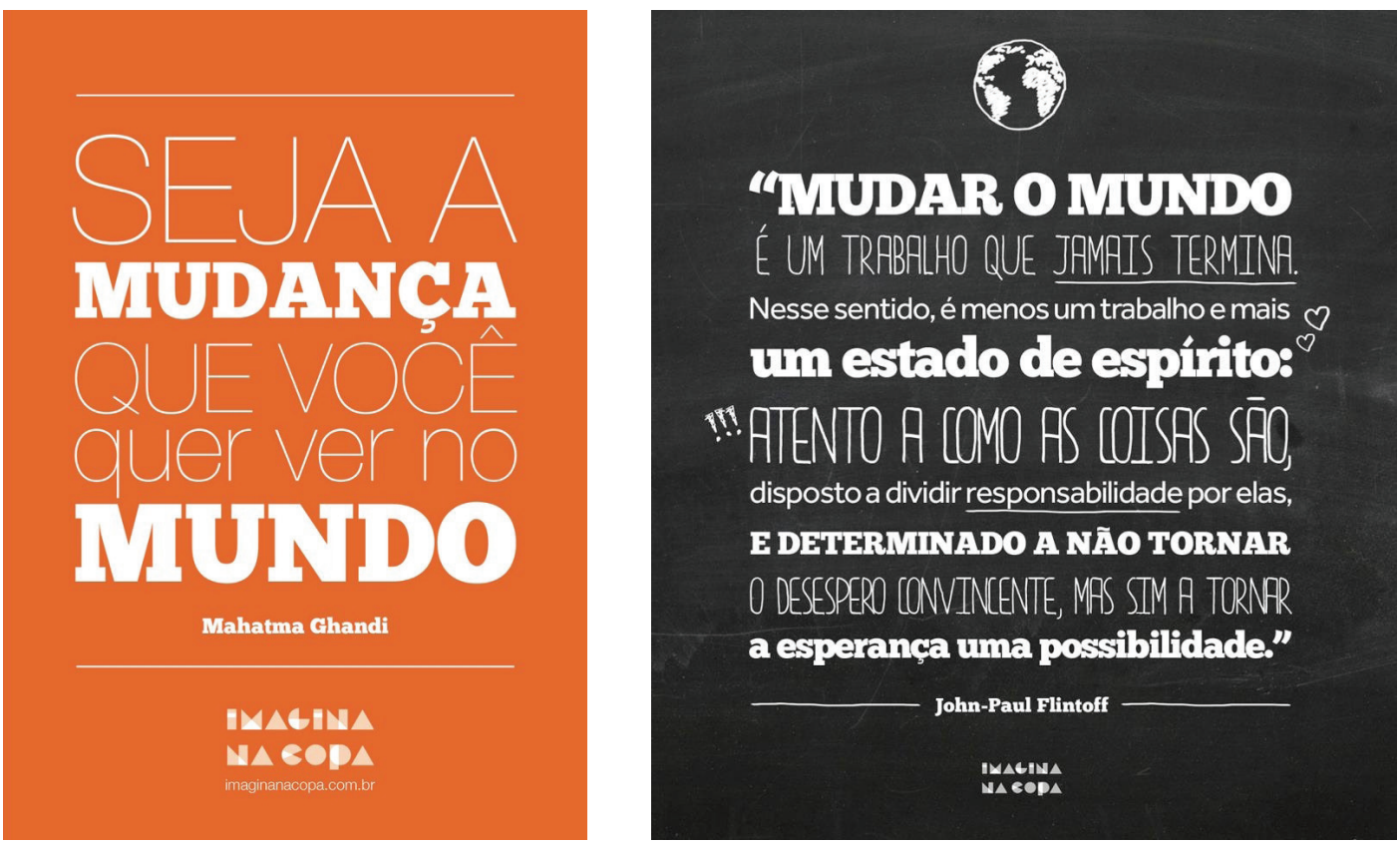

Fonte: publicações no perfil do projeto em 23 jan. 2013 (Fig. 3) e 16 jan. 2013 (Fig. 4).

Figura 5: Imagem da página do projeto Imagina na Copa na rede Facebook.
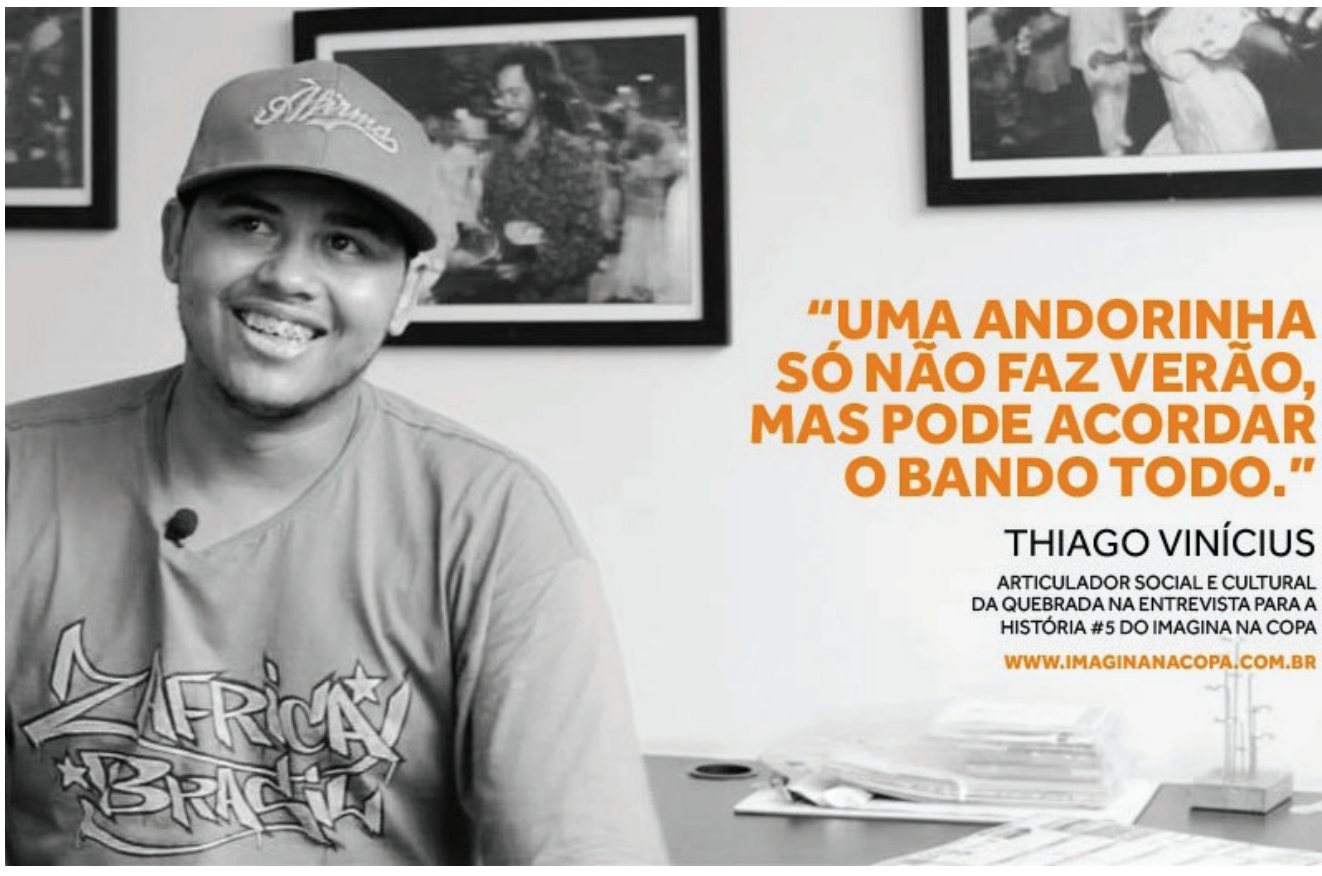

THIAGO VINÍCIUS

ARTICULADOR SOCIALE CULTURAL DAQUEBRADANAENTREVISTA PARA HISTÓRIA \#5 DO IMAGINANA COPA

WWW.IMAGINANACOPA.COM.BR 


\section{Considerações Finais}

Como forma de (in)conclusões, retomamos a ideia de comunidade para discussão, a partir da tese de Bauman (2003, p. 9). Para o autor, a "comunidade" é um tipo de mundo em que gostaríamos de viver, que ansiamos por possuir, mas que, "lamentavelmente", não está a nosso alcance. 0 exercício imaginativo promovido pelo Imagina na Copa em direção ao "paraíso perdido, ou paraíso ainda esperado", nas palavras de Bauman, transforma-se em um projeto de país, derivado da perspectiva da sociedade empreendedora (DRUCKER, 2011). Esse projeto é articulado em função da ação do jovem-ponte, o modelo de cultura construído pela pesquisa da Box1824 como tendência, como sinal de um cenário futuro derivado de sua liderança visionária.

É inegável a intersecção desse imaginário tanto com o novo espírito do capitalismo quanto com a atualização da retórica capitalista para o tempo em que vivemos. Consideradas essas duas perspectivas, compreendemos que a "imaginação" e 0 "sonho" são pontos de partida de uma leitura do mundo sustentada pela idealização da ação juvenil. A construção desse discurso ora é baseada no cientificismo dos resultados empíricos de pesquisa, ora é marcada pelo discurso competente da demonstração da "gente que faz", dos exemplos a serem replicados pela sociedade como um todo. 0 jovem emerge como o líder de uma "revolução sem revolução", uma onda reformista a ser propagada pela produção da "inspiração" como mercadoria simbólica.

0 empreendedorismo social é projetado como 0 ensaio de um mundo empreendedor, uma ideologia planetária concebida no contexto de um sistema capitalista, que é tanto gerador das mazelas sociais quanto o parâmetro para a concepção de suas soluções. Diante desse paradoxo fundamental, fica a questão: é possível imaginar uma mudança social efetiva derivada da conjunção entre a prática empreendedora, a psicologia positiva aplicada à ação social e a utopia esvaziada do caráter revolucionário?

\section{Referências}

ANDERSON, Benedict. Comunidades imaginadas: reflexões sobre a origem e a expansão do nacionalismo. Lisboa: Edições 70, 2005.

ANGENOT, Marc. El discurso social: los limites históricos de lo pensable y lo decible. Buenos Aires: Siglo XXI, 2010.

BAUMAN, Zygmunt. Vida para consumo. Rio de Janeiro: Zahar, 2008.

Comunidade: a busca por segurança no mundo atual. Rio de Janeiro: Zahar, 2003.

BERGER, Peter L.; LUCKMANN, Thomas. A construção social da realidade. Petrópolis: Vozes, 1985.

BOLTANSKI, Luc; CHIAPELLO, Ève. 0 novo espírito do capitalismo. São Paulo: Martins Fontes, 2009.

BUONANNO, Milly. Histórias de vida exemplares. Biografias. MATRIZes, ano 5, nº 1, 2011, p. 63-84. CAIAFA, Janice; ELHAJJI, Mohammed. Apresentação. In: (Orgs.) Comunicação e sociabilidade: 
cenários contemporâneos. Rio de Janeiro: Mauad X, 2007, p. 7-10.

CHARAUDEAU, Patrick. Discurso das mídias. São Paulo: Contexto, 2007.

DAHRENDORF, Ralf. Homo sociologicus. Lisboa: Quetzal, 2012.

DEFOURNY, Jacques. Empresa social. In: HESPANHA, Pedro et al. Dicionário internacional da outra economia. Coimbra: Almedina - CES, 2009, p. 188-192.

DEY, P.; STEYAERT, C. The politics of narrating social entrepreneurship. Journal of Enterprising Communities - people and places in the global economy, vol. 4, no.1, p. 85-108, 2010.

DRUCKER, Peter F. Inovação e espírito

empreendedor: prática e princípios. São Paulo:

Cengage Learning, 2011.

EHRENBERG, Alain. 0 culto da performance: da aventura empreendedora à depressão nervosa. Aparecida - SP: Idéias \& Letras, 2010.

FAIRCLOUGH, Norman. Discurso e mudança social. Brasília: Ed. UNB, 2001.

LAZZARAT0, Maurizio. As revoluções do capitalismo. Rio de Janeiro: Civilização Brasileira, 2006.

MARTIN, Roger L.; OSBERG, Sally. Social entrepreneurship: the case for definition. Stanford Social Innovation Review, p. 29-39, Spring 2007. Disponível em: < http://www.people.fas.harvard. edu/ hiscox/Martin0sberg.pdf > . Acesso em: 15 fev. 14 .

MATTELART, Armand. História da utopia

planetária: da cidade profética à sociedade global.

Porto Alegre: Sulina, 2002.

McLUHAN, Marshall. McLuhan por McLuhan: conferências e entrevistas (understanding me). Rio de Janeiro: Ediouro, 2005.
PRAD0, José L. Aidar. Convocações biopolíticas dos dispositivos comunicacionais. São Paulo: Educ / Fapesp, 2013.

Política da imagem na era da convocação. In: Significação ano 39, nº 37. São Paulo: ECA-USP, 2012, p. 167-187.

PROJETO SONHO BRASILEIRO. Pesquisa realizada pela agência Box1824, divulgada em 2011. Disponível em: < http://pesquisa.osonhobrasileiro.com.br/indexn. php >. Acesso em: 7 ago. 2014.

QUEM SE IMPORTA. Direção e Roteiro: Mara Mourão. Produção: Túlio Schargel. Com: Muhammad Yunnus; Bill Drayton; Vera Cordeiro e outros. Narração: Rodrigo Santoro. Brasil: Produzido por Grifa Filmes / Mamo Filmes, 2011. 1 DVD (90 min.), som, colorido. Distribuidora: Imovision. Gênero: Documentário.

QUINTÃO, Carlota. A reemergência do Terceiro Setor. In: VELOSO, Luísa; CARMO, Renato M. (Orgs). A constituição social da economia. Lisboa: Ed. Mundos Sociais, 2012, p. 123-153.

SILVERSTONE, Roger. Por que estudar a mídia? São Paulo: Loyola, 2002.

TRIVEDI, Chitvan; STOKOLS, Daniel. Social enterprises and corporate enterprises: fundamental differences and defining features. The Journal of Entrepreneurship, 20(1), p. 1-32, 2011.

WAGNER, Roy. A invenção da cultura. São Paulo: Cosac Naify, 2010. 


\section{The invention of a country of social entrepreneurs: "Imagina na Copa" and its project of Brazil}

\section{Abstract}

This study deals with the theme of social entrepreneurship, from its discursive dimension, through the analysis of the "Imagina na Copa", a digital platform that gives visibility to initiatives of Brazilian social entrepreneurs. The "community project" allows us to understand the articulation of social role (DAHRENDORF) of the social entrepreneur in the imagined country, in which the young Brazilians are protagonists and agents of "transformation" - articulated between individual positive attitude and cooperative work. The theoretical framework discusses the meanings of social entrepreneurship, its relationship with the Spirit of Capitalism, in its character of social discourse (ANGENOT); analyzes of the corpus are carried out from the theoretical and methodological approach of discourse analysis.

\section{Keywords}

Social entrepreneurship. Communication and discourse. Sociability. Consumption. Community.

\section{La invención de un país de emprendedores sociales: "Imagina na Copa" y su proyecto de Brasil}

\section{Resumen}

Este estudio aborda el tema de emprendedurismo social, desde su dimensión discursiva, a través del análisis de lo proyecto "Imagina na Copa", una plataforma digital que da visibilidad a las iniciativas de los emprendedores sociales brasileños. El "proyecto comunitario" nos permite entender la articulación del rol social (DAHRENDORF) del emprendedor social en el país imaginado, en la que los protagonistas son los jóvenes brasileños y agentes del "cambio" - articulada entre la actitud positiva individual y el trabajo cooperativo. El marco teórico discute los significados del emprendedurismo social, su relación con el espíritu del capitalismo, en su carácter de discurso social (ANGENOT); análisis del corpus se llevan a cabo desde el enfoque teórico y metodológico del análisis del discurso.

\section{Palabras clave}

Emprendedurismo social. Comunicación y discurso. Sociabilidad. Consumo. Comunidad. 


\section{Expediente}

A revista E-Compós é a publicação científica em formato eletrônico da Associação Nacional dos Programas de Pós-Graduação em Comunicação (Compós). Lançada em 2004, tem como principal finalidade difundir a produção acadêmica de pesquisadores da área de Comunicação, inseridos em instituições do Brasil e do exterior.

\section{E-COMPÓS I www.e-compos.org.br I E-ISSN 1808-2599}

Revista da Associação Nacional dos Programas de Pós-Graduação em Comunicação.

Brasília, v.18, n.1, jan./abri.. 2015.

A identificação das edições, a partir de 2008, passa a ser volume anual com três números.

\section{CONSELHO EDITORIAL}

Alexandre Rocha da Silva, Universidade Federal do Rio Grande do Sul, Brasil Alexandre Farbiarz, Universidade Federal Fluminense, Brasil Ana Carolina Damboriarena Escosteguy, Pontifícia Universidade Católica do Rio Grande do Sul, Brasil

Ana Carolina Rocha Pessôa Temer, Universidade Federal de Goiás, Brasil Ana Regina Barros Rego Leal, Universidade Federal do Piauí, Brasil André Luiz Martins Lemos, Universidade Federal da Bahia, Brasil Andrea França, Pontifícia Universidade Católica do Rio de Janeiro, Brasil Antonio Carlos Hohlfeldt, Pontifícia Universidade Católica do Rio Grande do Sul, Brasil

Arthur Ituassu, Pontifícia Universidade Católica do Rio de Janeiro, Brasil Álvaro Larangeira, Universidade Tuiuti do Paraná, Brasil Ângela Freire Prysthon, Universidade Federal de Pernambuco, Brasil César Geraldo Guimarães, Universidade Federal de Minas Gerais, Brasil Cláudio Novaes Pinto Coelho, Faculdade Cásper Líbero, Brasil Daisi Irmgard Vogel, Universidade Federal de Santa Catarina, Brasil Daniela Zanetti, Universidade Federal do Espírito Santo, Brasil Denize Correa Araujo, Universidade Tuiuti do Paraná, Brasil Eduardo Antonio de Jesus, Pontifícia Universidade Católica de Minas Gerais, Brasil

Eduardo Vicente, Universidade de São Paulo, Brasil

Elizabeth Moraes Gonçalves, Universidade Metodista de São Paulo, Brasil Erick Felinto de Oliveira, Universidade do Estado do Rio de Janeiro, Brasil Francisco Elinaldo Teixeira, Universidade Estadual de Campinas, Brasil Francisco Paulo Jamil Almeida Marques, Universidade Federal do Ceará, Brasil Gabriela Reinaldo, Universidade Federal do Ceará, Brasil Gisela Grangeiro da Silva Castro, Escola Superior de Propaganda e Marketing, Brasil

Goiamérico Felício Carneiro Santos, Universidade Federal de Goiás, Brasil Gustavo Daudt Fischer, Unisinos, Brasil

Herom Vargas, Universidade Municipal de São Caetano do Sul, Brasil
Itania Maria Mota Gomes, Universidade Federal da Bahia, Brasil Janice Caiafa, Universidade Federal do Rio de Janeiro, Brasil Jiani Adriana Bonin, Universidade do Vale do Rio dos Sinos, Brasil José Afonso da Silva Junior, Universidade Federal de Pernambuco, Brasil José Luiz Aidar Prado, Pontifícia Universidade Católica de São Paulo, Brasil Kati Caetano, Universidade Tuiuti do Paraná, Brasil

Lilian Cristina Monteiro França, Universidade Federal de Sergipe, Brasil Liziane Soares Guazina, Universidade de Brasília, Brasil Luíza Mônica Assis da Silva, Universidade de Caxias do Sul, Brasil Luciana Miranda Costa, Universidade Federal do Pará, Brasil Malena Segura Contrera, Universidade Paulista, Brasil Marcel Vieira Barreto Silva, Universidade Federal da Paraíba, Brasil Maria Ogécia Drigo, Universidade de Sorocaba, Brasil Maria Ataide Malcher, Universidade Federal do Pará, Brasil Maria Clotilde Perez Rodrigues, Universidade de São Paulo, Brasil Maria das Graças Pinto Coelho, Universidade Federal do Rio Grande do Norte, Brasil

Mauricio Ribeiro da Silva, Universidade Paulista, Brasil

Mauro de Souza Ventura, Universidade Estadual Paulista, Brasil Márcio Souza Gonçalves, Universidade do Estado do Rio de Janeiro, Brasil Micael Maiolino Herschmann, Universidade Federal do Rio de Janeiro, Brasil Mirna Feitoza Pereira, Universidade Federal do Amazonas, Brasil Nísia Martins Rosario, Universidade Federal do Rio Grande do Sul, Brasil Potiguara Mendes Silveira Jr, Universidade Federal de Juiz de Fora, Brasil Regiane Ribeiro, Universidade Federal do Paraná, Brasil Rogério Ferraraz, Universidade Anhembi Morumbi, Brasil Rose Melo Rocha, Escola Superior de Propaganda e Marketing, Brasil Rozinaldo Antonio Miani, Universidade Estadual de Londrina, Brasil Sérgio Luiz Gadini, Universidade Estadual de Ponta Grossa, Brasil Simone Maria Andrade Pereira de Sá, Universidade Federal Fluminense, Brasil Veneza Mayora Ronsini, Universidade Federal de Santa Maria, Brasil Walmir Albuquerque Barbosa, Universidade Federal do Amazonas, Brasil

\section{COMISSÃO EDITORIAL}

\section{Cristiane Freitas Gutfreind}

Pontifícia Universidade Católica do Rio Grande do Sul, Brasil

Irene Machado

Universidade de São Paulo, Brasil

Jorge Cardoso Filho

Universidade Federal do Reconcavo da Bahia, Brasil

Universidade Federal da Bahia, Brasil

$$
\begin{aligned}
& \text { REVISÃo DE TEXTOS I Press Revisão } \\
& \text { SECRETÁRIA EXECUTIVA I Helena Stigger } \\
& \text { EDITORAÇÃO ELETRÔNICA I Roka Estúdio }
\end{aligned}
$$

COMPÓS I www.compos.org.br

Associação Nacional dos Programas de Pós-Graduação em Comunicação

Presidente

\section{Eduardo Morettin}

Universidade de São Paulo, Brasil

eduardomorettin@usp.br

\section{Vice-presidente}

Inês Vitorino

Universidade Federal do Ceará, Brasil

ines@ufc.br

Secretária-Geral

Gislene da Silva

Universidade Federal de Santa Catarina, Brasil gislenedasilva@gmail.com 